\title{
A novel genotyping technique for discriminating LVAS-associated high-frequency variants in SLC26A4 gene
}

\author{
Chen Zhou ${ }^{1,2 \dagger}$, Xiangman Zou ${ }^{1,2+}$, Cuiying Peng ${ }^{2}$, Guoqiang Gao ${ }^{3}$ and Zifen Guo ${ }^{1,2^{*}}$ (1)
}

\begin{abstract}
An increasing number of biological and epidemiological evidence suggests that c.919-2A $>G$ and c.2168A $>G$ variants of solute carrier family 26, member 4 (SLC26A4) gene play a critical role in the development of large vestibular aqueduct syndrome (LVAS). In this study, we developed a rapid genotyping method for discriminating LVAS-associated high-frequency variants in SLC26A4 gene. The genotyping technique consists of $3^{\prime}$ terminal exonuclease-resistant phosphorothioate-modified allele specific primer extension mediated by exo ${ }^{+}$polymerase. In PCR amplification by Pfu polymerase, allelic specific primers perfectly matching wild type allele were extended while no specific products were yielded from primers targeting variant allele. Similarly, allelic specific primers perfectly matching variant allele were extended and no specific products were observed from primers targeting wild type allele. The clinical application of $3^{\prime}$ terminal phosphorothioate-modified allele specific primer extension mediated by Pfu polymerase identified both homozygous for SLC26A4 gene c.919-2A > G variant in two patients clinically diagnosed as LVAS by temporal bone CT scan. The genetic results from this method are consistent with that of DNA sequencing. The data suggest that exo ${ }^{+}$polymerase-mediated $3^{\prime}$ terminal phosphorothioate-modified primer extension is reliable in the identification of SLC26A4 gene high-frequency variant prior to high-resolution CT scan. The method is extremely suitable for quickly molecular etiologic screening and early diagnosis and aggressive prevention therapy of LVAS.
\end{abstract}

Keywords: Solute carrier family 26 member 4, Large vestibular aqueduct syndrome, Exo+ polymerase, Phosphorothioate modification

\section{Introduction}

Large vestibular aqueduct syndrome (LVAS) is an autosomal recessive genetic hearing loss disorder with a high incidence which is mainly accompanied by progressive and fluctuating hearing loss (Tong et al. 1997; Claros et al. 2017). It is well known that the solute carrier family 26 , member 4 (SLC26A4) gene plays a critical role in the development of LVAS, and about $90 \%$ of LVAS is closely attributed to SLC26A4 gene variants (Nishio et al. 2016; Chao et al. 2019; Kim et al. 2019). The human SLC26A4

\footnotetext{
*Correspondence: guozifen@aliyun.com

${ }^{\dagger}$ Chen Zhou and Xiangman Zou contributed equally to this work

${ }^{1}$ Institute of Pharmacy and Pharmacology, University of South China,

Hengyang, Hunan, China

Full list of author information is available at the end of the article
}

gene is mapped to chromosome 7q31, encompasses 21 exons and contains a $2343 \mathrm{bp}$ open reading frame encoding a protein of 780 amino acids. To date, more than 100 of SLC26A4 gene variants have been identified and described as causally related to hereditary hearing impairment (https://hereditaryhearingloss.org/).

Before the clinical application of gene diagnosis, the imageological examination was the only way of LVAS diagnosis and had stated clearly that LVAS is the most common inner ear malformation (Connor et al. 2019; Yang and Liu 2019).

Previous studies revealed that SLC26A4 gene variant has obvious racial specificity, LVAS patients from different races with unique variant spectra and different variant frequencies (Berrettini et al. 2005; Hu et al. 2007;
Springer Open

(c) The Author(s) 2020. This article is licensed under a Creative Commons Attribution 4.0 International License, which permits use, sharing, adaptation, distribution and reproduction in any medium or format, as long as you give appropriate credit to the original author(s) and the source, provide a link to the Creative Commons licence, and indicate if changes were made. The images or other third party material in this article are included in the article's Creative Commons licence, unless indicated otherwise in a credit line to the material. If material is not included in the article's Creative Commons licence and your intended use is not permitted by statutory regulation or exceeds the permitted use, you will need to obtain permission directly from the copyright holder. To view a copy of this licence, visit http://creativeco mmons.org/licenses/by/4.0/. 
Lee et al. 2008). For years, the interest in SLC26A4 gene variant closely associated with Chinese LVAS individuals has been focused on c.919-2A $>$ G and c. 2168A $>$ G variants (Hu et al. 2007; Zhu et al. 2012), The two most common types (c.919-2A > G and c. 2168A $>$ G) accounted for $69.1 \%$ (Hu et al. 2007) and 33.06\% (Guo et al. 2008) variants respectively. Therefore, screening the high-frequency variant can early diagnose LVAS patients and find variant carriers and then taking measures to prevent further hearing loss by keeping LVAS patients from cold and head injury.

We have previously reported that $\mathrm{exo}^{+}$polymerasemediated $3^{\prime}$ terminal exonuclease-resistant phosphorothioate-modified allele specific primer extension formed a molecular switch sensitive to single nucleotide discrimination (Zhang and Li 2003; Zhang et al. 2005). For $3^{\prime}$ allele-specific primers with phosphorothioate-modification, perfect-matched primer turns on and mismatched primer turns off DNA polymerization. $\mathrm{Exo}^{+}$polymerases generated products only from perfect-matched primers and no products from mismatched primers, which provided an unambiguous readout for yes or no in a specific variant detection assay. In this study, we will construct a double PCR technology platform mediated by variant sensitive molecular switch for rapid screening the SLC26A4 gene c.919-2A $>$ G and c.2168A > G high-frequency variants and explore strategies for clinical genetic diagnosis.

\section{Materials and methods Reagents}

Pfu DNA polymerase with strong $3^{\prime} \rightarrow 5^{\prime}$ exonuclease activity was purchased from TaKaRa Bio Inc. (Dalian, China). KOD-Plus-Mutagenesis Kit used in this study was obtained from TOYOBO Inc. (Shanghai, China). pMD19-T vector was the product of TaKaRa Bio Inc. (Dalian, China). Both unmodified primers and phosphorothioate-modified primers were synthesized commercially by TaKaRa Bio Inc. (Dalian, China).

\section{Primer design}

There are three types of primers: wild template preparation primers, mutagenesis primers and detection primers. The unmodified primers for wild type SLC26A4 gene preparation were designed based on the information of the Genebank database (NC_000007.14). The mutagenesis primers for SLC26A4 gene c.919-2A > G and c.2168A $>G$ variants through inverse PCR were designed to create point variants in the corresponding sites according to the Muta Primer 2.0 software. Allelic specific detection primers targeting wild and mutant templates were both designed with $3^{\prime}$ terminal phosphorothioate-modification. The $3^{\prime}$ terminal upstream to the -2 base ( $\mathrm{T}$ or $\mathrm{C}$ ) of the reverse primer of c.919$2 \mathrm{~A}>\mathrm{G}$ and the forward primer of c.2168A $>\mathrm{G}$ (A or $\mathrm{G}$ ) were the respective variant loci. All primers were synthesized by TaKaRa Bio Inc according to the following sequences as illustrated in Table 1, and the graphic illustration of primers is shown as Additional file 1 .

\section{Vector construction and identification}

Overlapping PCR generated SLC26A4 gene fragment harboring c.919-2A $>\mathrm{G}$ and c.2168A $>\mathrm{G}$ flanking sequence, which was subsequently added $A$ base and then inserted into the pMD19-T vector followed by transforming into E.coli JM109 competent cells. After $37^{\circ} \mathrm{C}$ incubation for $12 \mathrm{~h}$, some clones were formed on the LB-agar plates containing X-Gal, IPTG and Ampicillin. White clones were randomly picked up for bacilli PCR amplification reaction with the M13 primers as an initial identification of the inserted DNA overlapped fragment by their size, and $1.0 \mathrm{ml}$ bacilli of each positive clone were sent to Invitrogen Biotechnology Co. Ltd. (Shanghai, China) for DNA sequencing.

Inverse PCR according to the manufacturer's protocol was performed twice for site-directed mutagenesis of c. $919-2 \mathrm{~A}>\mathrm{G}$ and c. $2168 \mathrm{~A}>\mathrm{G}$ variant in SLC26A4 gene. Following the degradation of the methylated DNA template by $D p n I$ endonuclease, the mutant circular PCR product was transformed into E.coli JM109 competent cells again. Similarly, the SLC26A4 gene c.919-2A > G and c.2168A $>\mathrm{G}$ mutant template was also confirmed by sequence analysis.

\section{Extension of phosphorothioate-modified primers by exo ${ }^{+}$ polymerase}

Two-directional primer extension was setup. Following denaturation at $95{ }^{\circ} \mathrm{C}$ for $2 \mathrm{~min}$, the primer extension was carried out for 30 cycles as follows: $30 \mathrm{~s}$ for denaturation at $95{ }^{\circ} \mathrm{C}, 30 \mathrm{~s}$ for annealing at $60{ }^{\circ} \mathrm{C}$, and $20 \mathrm{~s}$ for extension at $72{ }^{\circ} \mathrm{C}$. After the 30 cycles, an extra extension of 2 min was done before the reaction mixture was cooled down to $4{ }^{\circ} \mathrm{C}$. The primer extension reaction was performed in a total volume of $30 \mu \mathrm{L}$ with $20 \mathrm{pg}$ of template, $0.2 \mathrm{mmol} / \mathrm{L} \mathrm{dNTP}, 10 \mathrm{Ku} / \mathrm{L}$ of polymerase, $10 \mathrm{pmol} / \mu \mathrm{L}$ of both sense and antisense primers, and $2.5 \mu \mathrm{L}$ of the $10 \times$ Pfu polymerase reaction buffer which provides a final concentration of $10 \mathrm{mmol} / \mathrm{L} \mathrm{KCl}, 20 \mathrm{mmol} / \mathrm{L}$ Tris $-\mathrm{HCl}\left(\mathrm{pH} 8.8\right.$ at $\left.25^{\circ} \mathrm{C}\right)$, $10 \mathrm{mmol} / \mathrm{L}\left(\mathrm{NH}_{4}\right)_{2} \mathrm{SO}_{4}, 2 \mathrm{mmol} / \mathrm{L} \mathrm{MgSO}_{4}, 0.1 \%$ Triton $\mathrm{X}-100$. Electrophoresis in a $2.0 \%$ agarose $\mathrm{EtBr}$ gel at $8 \mathrm{~V} / \mathrm{cm}$ in $0.5 \times \mathrm{TBE}$ buffer was used to check whether the two-directional primer extension products were produced or not. 
Table 1 Sequences of all the primers used in this study

\begin{tabular}{|c|c|}
\hline Primer name & sequence \\
\hline Primer1 for c.919-2A $>\mathrm{G}$ wild fragment & 5' TGCGTGTAGCAGCAGGAAGTAT 3' \\
\hline Primer2 for c.919-2A $>\mathrm{G}$ wild fragment & 5' CTCATTCTATTGCCCAGGCTTTCCAGGTTGGCTCCATA 3' \\
\hline Primer3 for c. $2168 \mathrm{~A}>\mathrm{G}$ wild fragment & 5' TATGGAGCCAACCTGGAAAGCCTGGGCAATAGAATGAG 3' \\
\hline Primer4 for $\mathrm{c} .2168 \mathrm{~A}>\mathrm{G}$ wild fragment & 5' TAGTCTTCATATCTACCTAGCAAGGTTAAT 3' \\
\hline primer5 for c. $919-2 \mathrm{~A}>\mathrm{G}$ mutagenesis & 5' GTTTTATTTCGGACGATAATTGCTACTGCCATTTCATATGGAGCC 3' \\
\hline primer6 for c. $919-2 \mathrm{~A}>\mathrm{G}$ mutagenesis & 5'GGCTCCATATGAAATGGCAGTAGCAATTATCGTCCGAAATAAAAC3' \\
\hline primer7 for c. $2168 \mathrm{~A}>\mathrm{G}$ mutagenesis & 5' TTTGACGGTCCGTGATGCTATACTCTATCTACAGAACC 3' \\
\hline primer8 for c. $2168 \mathrm{~A}>\mathrm{G}$ mutagenesis & 5' GGTTCTGTAGATAGAGTATAGCATCACGGACCGTCAAA 3' \\
\hline Primer9: Forward detection primer of c.919-2A $>\mathrm{G}$ & 5' TTTTTATAGACGCTGGTTGAGATTTT ${ }^{\mathbf{a}}$ 3' $^{\prime}$ \\
\hline $\begin{array}{l}\text { Primer10: Reverse detection primer of c. } 919-2 A>G \text { for } A \\
\text { allele }\end{array}$ & 5' GGCAGTAGCAATTATCGTCT $\underline{\text { 3' }}$ \\
\hline $\begin{array}{l}\text { Primer11: Reverse detection primer of c. } 919-2 A>G \text { for } G \\
\text { allele }\end{array}$ & 5' GGCAGTAGCAATTATCGTC $\underline{\mathbf{C}} 3^{\prime}$ \\
\hline $\begin{array}{l}\text { Primer12: Forward detection primer of } c .2168 \mathrm{~A}>\mathrm{G} \text { for } \mathrm{A} \\
\text { allele }\end{array}$ & 5' CACATTCTTTTTGACGGTCC $\underline{\text { AT 3' }}$ \\
\hline $\begin{array}{l}\text { Primer13: Forward detection primer of c. } 2168 \mathrm{~A}>\mathrm{G} \text { for } \mathrm{G} \\
\text { allele }\end{array}$ & 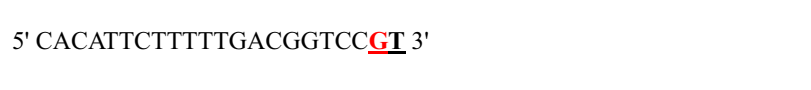 \\
\hline Primer14: Reverse detection primer of $c .2168 \mathrm{~A}>\mathrm{G}$ & 5' CCTCTTGAGATTTCACTTGGTTC $\underline{\mathbf{T G}}$ 3' \\
\hline
\end{tabular}

\section{High-frequency variants screening on clinical LVAS patient} $2.0 \mathrm{ml}$ of peripheral vein blood was obtained from two cases from the second affiliated hospital of University of South China, who were diagnosed as LVAS by the highresolution temporal bone $\mathrm{CT}$ imageological examination, and the human genomic DNA from the peripheral blood lymphocytes was extracted using phenol-chloroform extraction method. Pfu DNA polymerase combining with $3^{\prime}$ terminal phosphorothioate-modified primers targeting c. $919-2 \mathrm{~A}>\mathrm{G}$ and c. $2168 \mathrm{~A}>\mathrm{G}$ variants were utilized to screen the SLC26A4 gene on LVAS patients whether harboring either c.919-2A $>\mathrm{G}$ or c.2168A $>\mathrm{G}$ high-frequency variant. Furthermore, another PCR amplification was also carried out to separately get exon $7+8$ and exon19 fragment in SLC26A4 gene, which is suitable product including c.919-2A $>\mathrm{G}$ and c.2168A $>\mathrm{G}$ locus, and $1.0 \mathrm{ml}$ of the purified primer extended products were further used for sequence analysis from Invitrogen Biotechnology Co. Ltd. (Shanghai, China).

\section{Results}

\section{Construction and identification of vector}

PCR-generated wild DNA fragment separately harboring SLC26A4 gene c.919-2A > G and c.2168A > G flanking sequence were successfully overlapped (Fig. 1). After the overlapped DNA fragment was inserted into the pMD19$\mathrm{T}$ vector and subsequently transformed into E.coli JM109 competent cells, some white clones were formed on the

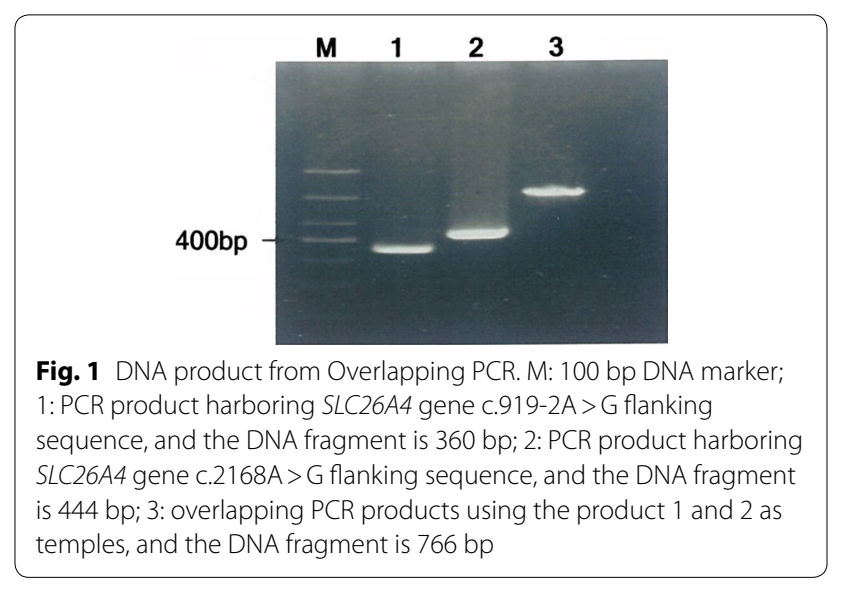

X-Gal/IPTG/ampicillin/LB-agar plates and randomly picked up for bacilli PCR amplification with the M13 primers to obtain positive clones. DNA sequencing not only confirmed the correctness of wild vector sequence as wild type template (Fig. 2a, c), and also documented the mutagenesis of c.919-2A $>\mathrm{G}$ and c. $2168 \mathrm{~A}>\mathrm{G}$ through inverse PCR: the existence of SLC26A4 gene c.919-2G and c.2168G variants in the mutant vector as mutant type template (Fig. 2b, d).

\section{Nucleotide discrimination by exo $^{+}$polymerase}

The data illustrated in Table 2 and Fig. 3 clearly showed that c.919-2A > G and c.2168A $>\mathrm{G}$ allelic 


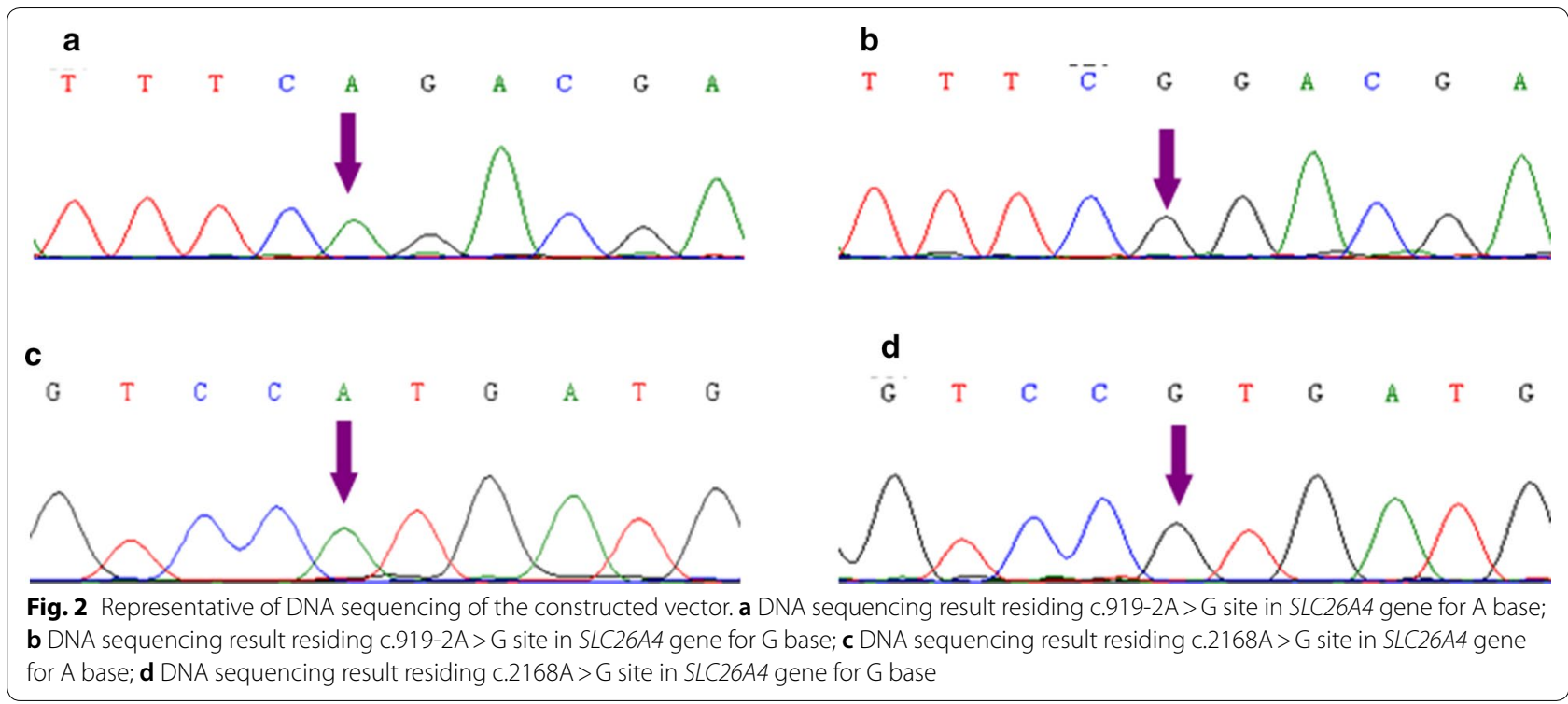

Table 2 Discrimination of c.919-2A $>$ G and c.2168A $>$ G mutations in SLC26A4 gene through the combination of $3^{\prime}$ phosphorothioate-modified primers and Pfu DNA polymerase

\begin{tabular}{|c|c|c|c|c|}
\hline Lane & Template & Mutation locus & Primer ( $3^{\prime}$ base-pairing with template) & $\begin{array}{l}\text { Product } \\
\text { (Yes } \\
\text { or No) }\end{array}$ \\
\hline 1 & Wild template & c. $919-2 A>G$ & c.919-2A allele (matched) & Yes \\
\hline 2 & Wild template & c. $919-2 A>G$ & c.919-2G allele (mismatched) & No \\
\hline 3 & Wild template & $c .2168 A>G$ & c.2168A allele (matched) & Yes \\
\hline 4 & Wild template & c. $2168 \mathrm{~A}>\mathrm{G}$ & c.2168G allele (mismatched) & No \\
\hline 5 & Wild template & c.919-2A>G+c.2168A>G & c.919-2A allele + c.2168A allele (matched) & Yes \\
\hline 6 & Wild template & c.919-2A>G+c.2168A>G & c.919-2G allele + c.2168G allele (mismatched) & No \\
\hline 7 & Mutant template & c. $919-2 A>G$ & c.919-2G allele (matched) & Yes \\
\hline 8 & Mutant template & c. $919-2 A>G$ & c.919-2A allele (mismatched) & No \\
\hline 9 & Mutant template & $c .2168 A>G$ & c.2168G allele (matched) & Yes \\
\hline 10 & Mutant template & $c .2168 A>G$ & c.2168A allele (mismatched) & No \\
\hline 11 & Mutant template & c.919-2A>G+c.2168A>G & c.919-2G allele + c.2168G allele (matched) & Yes \\
\hline 12 & Mutant template & c.919-2A>G+c.2168A>G & c.919-2A allele + c.2168A allele (mismatched) & No \\
\hline
\end{tabular}

specific primers perfectly matching wild type allele template were extended while no products were produced from point-mutated LVAS-associated mutant type allele template, and also allelic specific primers perfectly matching point-mutated LVAS-associated mutant type allele template were extended but no products were observed from wild type allele template. Furthermore, we carried out double PCR for SLC26A4 gene c.919-2A $>\mathrm{G}$ and c.2168A $>\mathrm{G}$ variants identification, and similarly, the matched primer extension was extended while the mismatched primer was not. But it was important to remind that duplex PCR generated an additional 518 bp nonspecific fragment regardless of primers perfectly matching constructed vector template or not, which was the product from the pair of amplification primer consisting of the forward detection primer of c.919-2A $>\mathrm{G}$ and the reverse detection primer of c. $2168 \mathrm{~A}>$ G. Since $3^{\prime} \rightarrow 5^{\prime}$ exonuclease activity of high-fidelity DNA polymerase can efficiently detect and proofread the mismatched base of the allele specific primer, once high-fidelity DNA polymerase combining with $3^{\prime}$ terminal exonucleaseresistant phosphorothioate-modified allele specific primer, the perfect-matched primer turned on and the mismatched primer turned off DNA polymerization. That provides an unambiguous readout for yes or no 


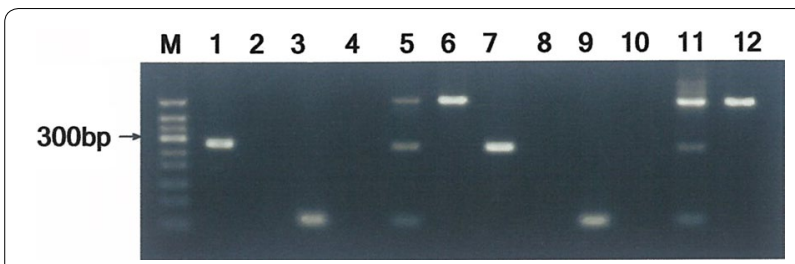

Fig. 3 Discrimination of SLC26A4 gene c.919-2A>G and c. $2168 \mathrm{~A}>\mathrm{G}$ variants by Pfu DNA polymerase-mediated phosphorothioate-modified primer extension. $\mathrm{M}$ is $50 \mathrm{bp}$ DNA marker; Lanes 1 and 8 is specific primer extension products from the primer of c.919-2A>G site for A allele, Lanes 2 and 7 are specific primer extension products from the primer of c.919-2A $>G$ site for $G$ allele, Lanes 3 and 10 are specific primer extension products from the primer of c.2168A>G site for A allele, Lanes 4 and 9 are specific primer extension products from the primer of c.2168A $>G$ site for $G$ allele, Lanes 5 and 12 are specific primer extension products from primer mixture of c.919-2A > G site for A allele and c.2168A $>G$ site for A allele, Lanes 6 and 11 are specific primer extension products from primer mixture of c.919-2A>G site for $G$ allele and c.2168A $>G$ site for $G$ allele; Lanes 1 to 6 are the PCR products using wild vector as wild template; Lanes 7 to 12 are the PCR products using mutant vector as mutant template. The specific DNA product targeting c.919-2A>G and c.2168A $>\mathrm{G}$ loci is $280 \mathrm{bp}$ and 65 bp respectively. Lanes 5, 6, 11 and 12 generate an extra 518 bp nonspecific fragment from a pair of amplification primers consisting of the forward detection primer of c.919-2A > G and the reverse detection primer of c.2168A>G

in single nucleotide discrimination: only the perfectmatched phosphorothioate-modified primer extension mediated by pfu DNA polymerase generated specific products and the mismatched primers extension not.

\section{Clinical application on screening the SLC26A4 high-frequency variant}

Pfu DNA polymerase-mediated phosphorothioate-modified primer extension was used to identify the $S L C 26 A 4$ gene variant on the LVAS patients who had been diagnosed as LVAS by temporal bone CT scan. The two LVAS patients both harbored c.919-2A $>$ G variant and were both homozygous for c.919-2A $>\mathrm{G}$ variant confirmed by DNA sequencing (Fig. 4).

\section{Discussion}

LVAS is frequently seen in children and teenagers, and congenital or acquired sensorineural hearing loss is its main manifestation. Now high-resolution temporal bone $\mathrm{CT}$ and MRI imageological examination are still the gold standards and a prerequisite for the correct diagnosis of LVAS. However, most domestic hospitals not only lack the requirement suitable for imageological diagnosis but also have no technologies that seem appropriate. As a result, most LVAS patients cannot receive timely correct diagnosis so that the doctor cannot provide effective treatment and prevention advice to him. Thankfully, with the clinical application of deafness-associated gene variant screening, it has demonstrated the particular advantages in the etiologic diagnosis of deafness.

Numerous studies indicate that c.919-2A $>$ G and c. $2168 \mathrm{~A}>\mathrm{G}$ variants in SLC26A4 gene are the highfrequency variants associated with Chinese LVAS individuals( $\mathrm{Hu}$ et al. 2007; Guo et al. 2008; Jiang et al. 2010; Li et al. 2011), which is similar to other patients in East Asia(Shin et al. 2012; Tsukamoto et al. 2003) and benefits SLC26A4 gene high-frequency variant
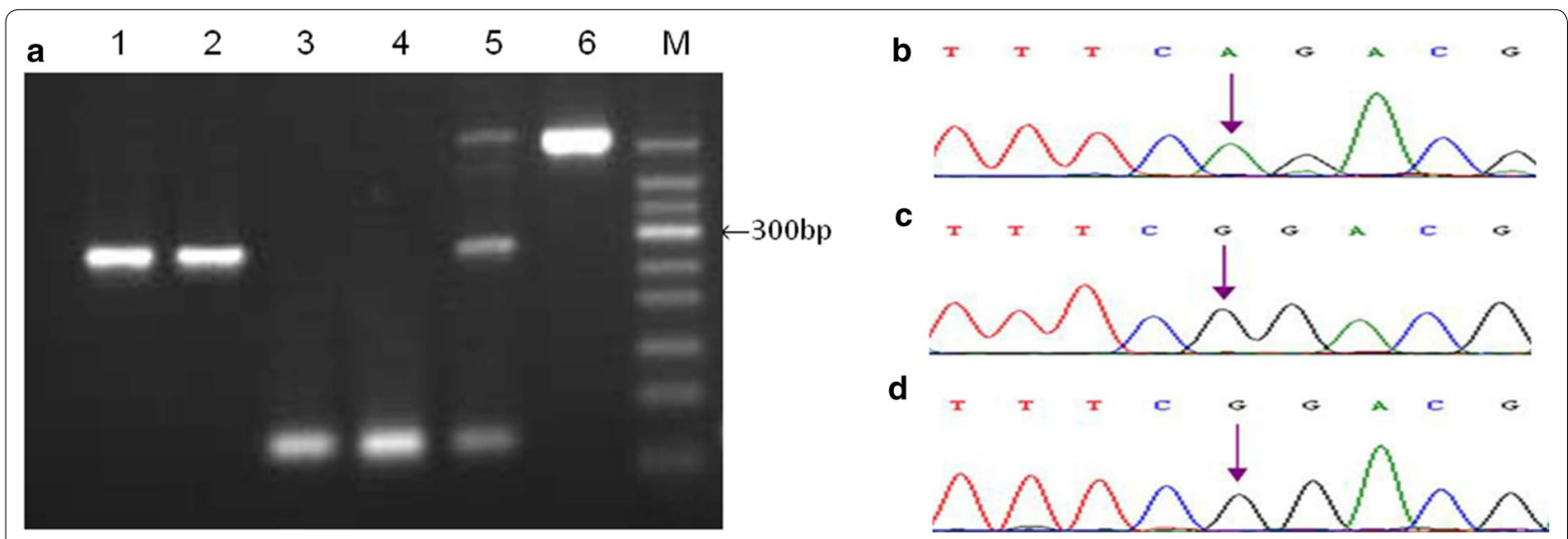

Fig. 4 The clinical application of Pfu DNA polymerase-mediated 3 ' terminal phosphorothioate-modified primer extension on screening the SLC26A4 high-frequency variant. a M is 50 bp DNA marker; Lanes 1, 2, 5 and 6 are specific primer extension products from primer mixtures of c.919-2A > G site for $\mathrm{G}$ allele and c.2168A $>\mathrm{G}$ site for $\mathrm{G}$ allele, which perfectly match mutant template; Lanes 3 and 4 are specific primer extension products from primer mixtures of c.919-2A > G site for A allele and c.2168A $>\mathrm{G}$ site for A allele, which perfectly matches wild template. Lanes 1 and 3 represent LVAS case1, and Lanes 2 and 4 represent LVAS case2. Lanes 5 is mutant vector as the positive control; Lanes 6 is wild vector as the negative control. b, c and $\mathbf{d}$ Sequence analysis of SLC26A4 gene. b Represents healthy volunteer, $\mathbf{c}$ and $\mathbf{d}$ respectively represent LVAS case 1 and 2 
screening in clinical application. Remarkably, none can effectively cure LVAS patients from etiology to symptoms until now, so early diagnosis and aggressive prevention therapy have great practical significance in preventing hearing further decline. Detecting LVASassociated high-frequency variant c.919-2A $>$ G and c. $2168 \mathrm{~A}>\mathrm{G}$ is extremely useful in the early diagnosis and intervention of LVAS, and the current research has focused on how to quickly screen SLC26A4 gene variant for foundationally preventing the occurrence of LVAS. Prohibiting either c.919-2A $>$ G or c. 2168 A $>$ G variant carrier from marrying another one with the same variant is thus the most effective way to protect the occurrence of LVAS.

As we all know, many gene variants assay technologies have been developed over the past decades, and the most popular methods are different variants of allele-specific primer extension mediated by DNA polymerases: Highthroughput sequencing, Sanger's method, restriction fragment length polymorphism (RFLP), multiplex ligation-dependent probe amplification (MLPA) and so on. High-throughput sequencing is a revolutionary technological innovation in gene sequencing researches and also known as next-generation sequencing (NGS). Although NGS is characterized by low cost and high-throughput data making it widely applied in multi-level researches, a high rate of false positives and requirement for prior PCR amplification or demands for expensive equipment remain the major obstacles to their effective wide applications. Sanger's method is also known as the "chain-termination method" and still considered the gold standard of gene sequencing technology today since it provides a high degree of accuracy and long-read capabilities, but the low throughput and high cost of sample preparation make it difficult to support a diverse range of applications in many research areas. RFLP is based on the alterations in restriction sites, so it is not suitable to assay gene variants not residing within restriction sites. MLPA relies on sequence-specific probe hybridization of genomic DNA, followed by multiplex-PCR amplification of the hybridized probe, so a suitable DNA extraction method must be chosen to keep DNA integrity and purity. Undoubtedly, exo + polymerase-mediated phosphorothioatemodified primer extension bypasses the limitation of template-dependent product generation by exo + polymerases through exonuclease-digestible allele-specific primers extension. Generally, it is easy to operate, economic and reliable, and these advantageous features make it very suitable for clinical genetic detection and variant screening. So in this study, we applied the variant sensitive molecular switch consisting of $3^{\prime}$ terminal exonuclease-resistant phosphorothioate-modified allele specific primer combining $\mathrm{exo}^{+}$polymerase in single-base discrimination of c.919-2A $>\mathrm{G}$ and c.2168A $>\mathrm{G}$ variants in SLC26A4 gene.

In our present study, the data from DNA sequence analysis proved that large amounts of wild and mutant type templates were successfully prepared by inserting the SLC26A4 gene overlapped PCR products into the pMD19-T vector and inverse PCR respectively. The two-directional primer extension showed that exo $^{+}$polymerases, combining $3^{\prime}$ terminal phosphorothioate-modified mismatched primer, work as an off-switch in DNA polymerization, the perfect match primer turned on and the mismatched primer turned off DNA polymerization respectively. So only allelic specific primer perfectly matching template yielded specific PCR product while allelic specific primer mismatching template not, which provided an unambiguous readout for yes or no in single nucleotide discrimination. The consequence of the off-switch effect resulted from the exonuclease-resistant property of the phosphorothioate-modification that blocked mismatched base excision of the primer during $3^{\prime} \rightarrow 5^{\prime}$ exonuclease proofreading procedure. Remarkably, an extra 518 bp nonspecific fragment was generated from the constructed vector template regardless of primers perfectly matching or not, while no nonspecific fragment was produced from the genomic DNA. The extra $518 \mathrm{bp}$ nonspecific fragment was the product from the pair of amplification primer consisting of the forward detection primer of c.919-2A $>\mathrm{G}$ and the reverse detection primer of c.2168A $>$ G. Of course, owing to ineffective amplification when using genomic DNA as the PCR template, the additional $518 \mathrm{bp}$ nonspecific product was not yielded. So when we applied Pfu DNA polymerase-mediated phosphorothioate-modified primer extension to screening the SLC26A4 gene on LVAS patients diagnosed as LVAS by temporal bone CT scan whether harboring c.919-2A > G or c.2168A $>\mathrm{G}$ variant, we could only observe specific PCR product without 518 bp nonspecific fragment. Actually, when using primer mixtures of c.919-2A $>$ G site for $G$ allele and c.2168A $>G$ site for $G$ allele, only specific primer of c.919-2A $>G$ site for $G$ allele yielded specific PCR product, which showed that the two LVAS patients both harbored c.919-2A $>$ G variant. For further identifying the allele type of LVAS patients, the double PCR from primer mixtures of c.919-2A $>$ G site for A allele and c. $2168 \mathrm{~A}>\mathrm{G}$ site for $\mathrm{A}$ allele were carried out again. On the contrary, not specific primer of c.919-2A $>G$ site for A allele but c.2168A $>\mathrm{G}$ site for A allele yielded specific PCR products. Thus it showed that both LVAS cases were homozygous for c.919-2A $>$ G variant. Moreover, DNA sequencing also confirmed the reliability of $\mathrm{exo}^{+}$polymerase-mediated phosphorothioate-modified primer extension in the identification SLC26A4 c.919$2 \mathrm{~A}>\mathrm{G}$ and c.2168A $>\mathrm{G}$ variant prior to high-resolution 
CT scan. The method is extremely suitable for quickly molecular etiologic screening. As an important testing means, genetic diagnosis of c. $919-2 \mathrm{~A}>\mathrm{G}$ and c.2168A $>\mathrm{G}$ variants and imageological examination are complementary with each other and can improve early diagnosis and deepen aggressive prevention therapy of LVAS.

Therefore, an easy, cheap and fast molecular diagnostics of c. $919-2 \mathrm{~A}>\mathrm{G}$ and c.2168A $>\mathrm{G}$ variants in SLC26A4 gene will greatly benefit patients. Through the wide application in clinical otology, genetic diagnostic techniques can guide pre-lingual deaf patients as soon as possible to make use of residual hearing with hearing aids or implanted electronic cochlea for preventing variable dumb and avoiding any further damage to the hearing of deafness patients themselves; More importantly, it can also be used for the assessment of the risk of postlingual deaf patients, prenatal diagnosis or prognosis, and patients with the marriage, birth genetic information to prevent the occurrence of LVAS patient fundamentally.

\section{Supplementary information}

Supplementary information accompanies this paper at https://doi. org/10.1186/s13568-020-01102-7.

Additional file 1. Graphic illustration of primer sequences.

\section{Authors' contributions}

Guo Zifen conceived and designed the research. Guo Zifen and Zhou Chen conducted the experiments. Gao Guoqiang contributed peripheral vein blood of clinical LAVS cases. Guo Zifen and Peng Cuiying analyzed data. Zhou Chen and Xiangman Zou wrote the manuscript. All authors read and approved the manuscript.

\section{Funding}

This work was partially funded by the Natural Science Foundation of Hunan Province (No.2018JJ2350) and the key project of the Education Department of Hunan Province (No.19A419).

\section{Availability of data and materials}

The datasets used and/or analyzed during the current study are available from the corresponding author on reasonable request.

\section{Ethics approval and consent to participate}

The study was conducted after agreement from the ethics committee of University of South China and with two patients and a healthy volunteer' informed consent statement.

\section{Consent for publication}

Not applicable.

\section{Competing interests}

The authors declare that they have no competing interests.

\section{Author details}

${ }^{1}$ Institute of Pharmacy and Pharmacology, University of South China, Hengyang, Hunan, China. ${ }^{2}$ Hunan Province Cooperative Innovation Center for Molecular Target New Drug Study, Hengyang, Hunan, China. ${ }^{3}$ The Second Affiliated Hospital, University of South China, Hengyang, Hunan, China.

Received: 10 January 2020 Accepted: 8 September 2020 Published online: 15 September 2020

\section{References}

Berrettini S, Forli F, Bogazzi F, Neri E, Salvatori L, Casani AP, Franceschini SS (2005) Large vestibular aqueduct syndrome: audiological, radiological, clinical, and genetic features. Am J Otolaryngol 26:363-371

Chao JR, Chattaraj P, Munjal T, Honda K, King KA, Zalewski CK, Chien WW, Brewer CC, Griffith AJ (2019) SLC26A4-linked CEVA haplotype correlates with phenotype in patients with enlargement of the vestibular aqueduct. BMC Med Genet 20:118

Claros P, Fokouo JV, Claros A (2017) Cochlear implantation in patients with enlarged vestibular aqueduct. A case series with literature review. Cochlear Implants Int 18:125-129

Connor SEJ, Dudau C, Pai I, Gaganasiou M (2019) Is CT or MRI the optimal imaging investigation for the diagnosis of large vestibular aqueduct syndrome and large endolymphatic sac anomaly? Eur Arch Otorhinolaryngol 276:693-702

Guo YF, Liu XW, Guan J, Han MK, Wang DY, Zhao YL, Rao SQ, Wang QJ (2008) GJB2, SLC26A4 and mitochondrial DNA A1555G mutations in prelingual deafness in Northern Chinese subjects. Acta Otolaryngol 128:297-303

Hu H, Wu L, Feng Y, Pan Q, Long Z, Li J, Dai H, Xia K, Liang D, Niikawa N, Xia J (2007) Molecular analysis of hearing loss associated with enlarged vestibular aqueduct in the mainland Chinese: a unique SLC26A4 mutation spectrum. J Hum Genet 52:492-497

Jiang L, Feng Y, Chen H, He C, Mei L (2010) An investigation of SLC26A4 gene mutation in nonsydromic hearing impairment in Hunan province of China. Lin Chung Er Bi Yan Hou Tou Jing Wai Ke Za Zhi 24:587-591

Kim MA, Kim SH, Ryu N, Ma JH, Kim YR, Jung J, Hsu CJ, Choi JY, Lee KY, Wangemann P, Bok J, Kim UK (2019) Gene therapy for hereditary hearing loss by SLC26A4 mutations in mice reveals distinct functional roles of pendrin in normal hearing. Theranostics 9:7184-7199

Lee KY, Choi SY, Bae JW, Kim S, Chung KW, Drayna D, Kim UK, Lee SH (2008) Molecular analysis of the GJB2, GJB6 and SLC26A4 genes in Korean deafness patients. Int J Pediatr Otorhinolaryngol 72:1301-1309

Li H, Li HB, Mao J, Liu MJ, Cheng HB, Li SL, Chen Y (2011) Genetic screening of mutation hot-spots for nonsyndromic hearing loss in southern Jiangsu province with SNaPshot. Zhonghua Yi Xue Yi Chuan Xue Za Zhi 28:383-386

Nishio A, Ito T, Cheng H, Fitzgerald TS, Wangemann P, Griffith AJ (2016) SLC26A4 expression prevents fluctuation of hearing in a mouse model of large vestibular aqueduct syndrome. Neuroscience 329:74-82

Shin JW, Lee SC, Lee HK, Park HJ (2012) Genetic screening of GJB2 and SLC26A4 in korean cochlear implantees: experience of soree ear clinic. Clin Exp Otorhinolaryngol 5:S10-S13

Tong KA, Harnsberger HR, Dahlen RT, Carey JC, Ward K (1997) Large vestibular aqueduct syndrome: a genetic disease? Am J Roentgenol 168:1097-1101

Tsukamoto K, Suzuki H, Harada D, Namba A, Abe S, Usami S (2003) Distribution and frequencies of PDS (SLC26A4) mutations in Pendred syndrome and nonsyndromic hearing loss associated with enlarged vestibular aqueduct: a unique spectrum of mutations in Japanese. Eur J Hum Genet 11:916-922

Yang L, Liu J (2019) Comparative Analysis of CT and MRI Diagnosis of Large Vestibular Aqueduct Syndrome (LVAS) in Children. J Coll Physicians Surg Pak 29:753-756

Zhang J, Li K (2003) On-off regulation of 3' exonuclease excision to DNA polymerization by Exo+ ${ }^{+}$polymerase. J Biochem Mol Biol 36:525-528

Zhang J, Li K, Pardinas JR, Sommer SS, Yao KT (2005) Proofreading genotyping assays mediated by high fidelity exo ${ }^{+}$DNA polymerases. Trends Biotechnol 23:92-96

Zhu Q, Zang W, Yuan Y, Han H, Zhang X, Jiang X, Ren X, Feng C, Lu H (2012) Investigation of SLC26A4 mutations associated with inner ear malformations. Lin Chung Er Bi Yan Hou Tou Jing Wai Ke Za Zhi 26:22-26

\section{Publisher's Note}

Springer Nature remains neutral with regard to jurisdictional claims in published maps and institutional affiliations. 